\title{
Comparative Analysis on Performance and Emission Characteristic of Diesel Engine Fueled with Heated Coconut Oil and Diesel Fuel
}

\author{
A.T. Hoang ${ }^{1,4^{*}}$, M.M. Noor ${ }^{2}$, and X.D. Pham ${ }^{3}$ \\ ${ }^{1}$ Faculty of Mechanical Engineering, Ho Chi Minh city University of Transport \\ No.2, D3 Road, Binh Thanh District, Ho Chi Minh city, Vietnam \\ ${ }^{2}$ Automotive Engineering Centre, Universiti Malaysia Pahang \\ 26600 Pekan, Pahang, Malaysia \\ ${ }^{3}$ Faculty of Marine Engine, Vietnam Maritime University \\ 484 Lach Tray, Haiphong, Vietnam \\ ${ }^{4}$ Department of Mechanical Engineering, The Central Transport College VI \\ 189 Kinh Duong Vuong, District 6, Ho Chi Minh city, Vietnam \\ *Email: tuan.hoang@ut.edu.vn, muhamad@ump.edu.my
}

\begin{abstract}
Alternative fuel and renewable energy is becoming important issue due to unstable fuel supply and price. Recently, bio-fuels are much interested because of their beneficial effects on environment, agriculture and economic development. Raw vegetable oils - a kind of bio-fuels, even though it has many disadvantages, are potential renewable fuel replaced for ever-exhausted fossil fuel. In this work, vegetable oil available in the South of Vietnam such as raw coconut oil is used by heating up to aim at reducing its high viscosity, surface tension, density and meeting the fuel requirements. Experimental and comparative study is carried out on an $80 \mathrm{hp}$ small marine diesel engine fueled with heated coconut oil (HCO) and fossil diesel fuel. The results of engine performance and emission characteristics are measured. The results show that, specific fuel consumption, $\mathrm{CO}, \mathrm{HC}$ and smoke emissions are higher, but thermal efficiency and $\mathrm{NO}_{\mathrm{x}}$ emission are lower as using $\mathrm{HCO}$ in comparison with diesel fuel. Besides, this study also denotes that, heated raw coconut oil up to $100{ }^{\circ} \mathrm{C}$ is considered as the most proper fuel to achieve the engine performance and emission characteristics, which are equal to diesel fuel.
\end{abstract}

Keywords: Bio-fuels; emission; engine performance; heating method; vegetable oil

\section{INTRODUCTION}

Green energy and alternative fuels should be based on the criterions such as availability, low cost, benefit for environment and satisfying the human's demands on energy [1]. In developing countries, crises and depletion of fossil fuel as well as environmental pollution are extremely serious issues. Nowadays, a new attention on reducing the greenhouse gases and increasing the clean development of global are being interested and promoted the using of renewable or bio related fuels such as bio-alcohol, vegetable oils, biomass, biogas, biodiesel, dimethyl ether [2]. However, some of them can be used directly to replace fossil fuel, but it is compulsory for improving their properties in order to bring the similar properties to traditional fuels. Especially, there are several researches aiming at using vegetable oils or animal fat and the converted products based on vegetable oils (VOs) or animal fats (AFs) into potential and easy-using alternative fuels for diesel engines [3]. 
In the South of Vietnam, the rural products are very abundant such as sunflower oil, peanut oil, rubber seed oil, coconut oil, jatropha oil, catfish fat. These oils could be absolutely used as fuels for diesel engine. Some of rural people have used coconut oil or catfish fat for small fishing vessels in the South of Vietnam and used jatropha oil on generator diesel engines in the Middle of Vietnam. Thus, using VOs for diesel engine may bring many benefits such as sustainability, rural development, and reduction in toxic emissions. However, raw vegetable oils' high viscosity, density and surface tension may cause the poor atomization, lower evaporation, heterogeneous mixture and resulting in inferior of diesel engine power and emission. Some physicochemical and combustive characteristics of fuel-based-pure vegetable oil are shown in Figure 1.

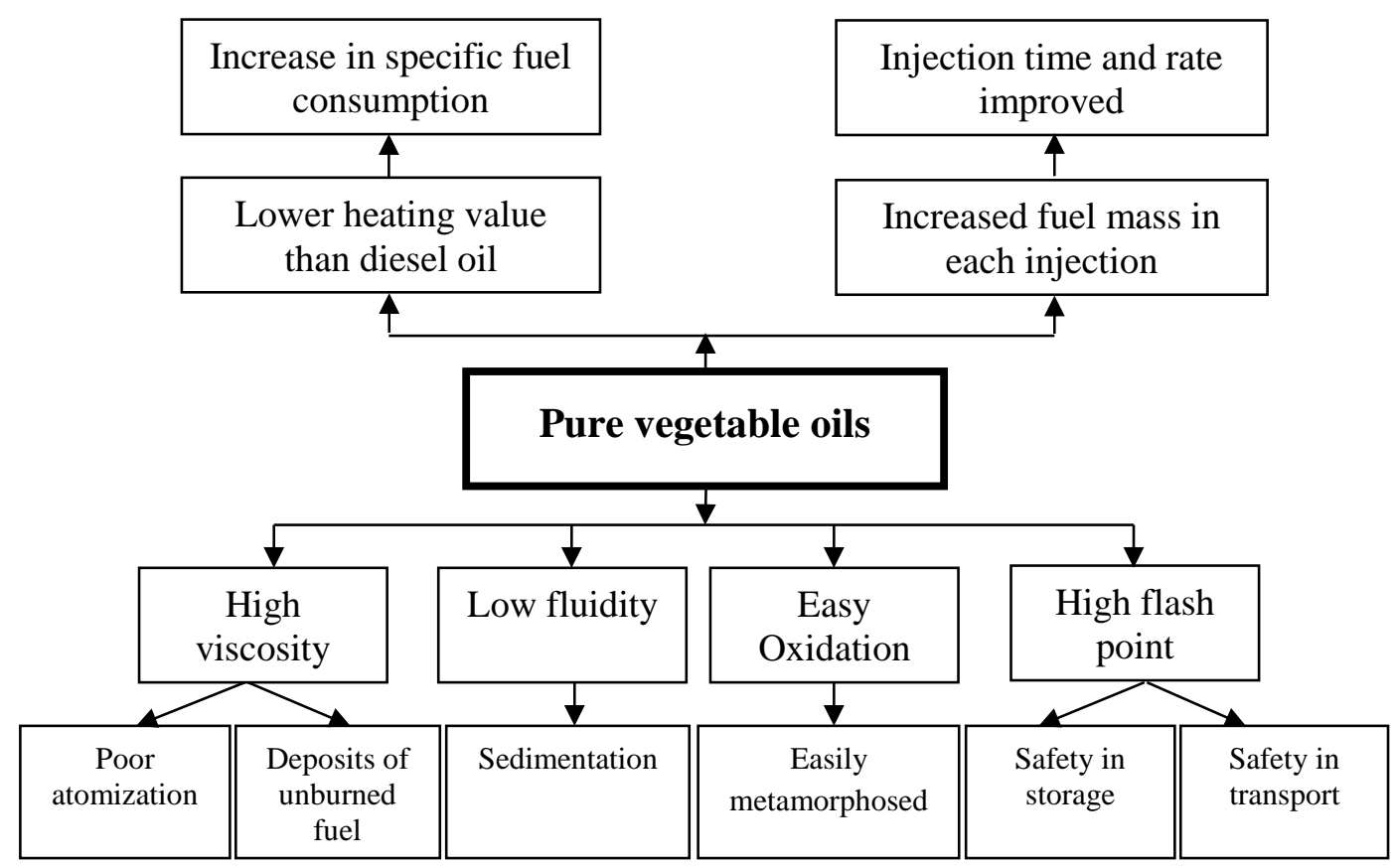

Figure 1. Pure vegetable oil characteristics [4].

Many researchers have shown the method for improving the disadvantages of vegetable oils such as:

\section{Transesterification to Biodiesel}

Biodiesels were considered as transesterification products after moving glycerol from bio-oils, which include VOs or Afs [5]. The biodiesel was named and described its applicability for diesel engines [6]. Biodiesel advantages such as lower pollution and renewable sources were interested in applying on diesel engines to replace fossil fuel [7]. Using catalysts in the reaction between VOs or AFs and methanol, 2-propanol, ethanol, and buthanol was carried out for transesterification. The transesterification was potential and cheap method of transforming bio-oils with the large structure and non-straight-chain molecules into smaller structure, straight-chain molecules aiming at meeting the requirement of fuel standard for diesel engines [8]. The biodiesel properties such as viscosity, cloud point, heat of combustion, volatility were similar to diesel fuel. The density and cetane number of biodiesel were higher than those of fossil diesel fuels [9]. 
Besides, using biodiesel as fuel was better than fossil fuel because of its biodegradability, containing oxygen, sulfur and aromatic content $[2,10]$.

\section{Emulsion with Low Viscosity Liquid}

Emulsion of two non-miscible fluids was a steady dispersion that continuously produced a droplets phase and reduced the surface tension, maximized the contact areas to make emulsions [1]. An experimental research results about using palm oil emulsions for a diesel engine showed that unburned hydrocarbon ( $\mathrm{HCs}$ ), carbon monoxide $(\mathrm{CO})$, and carbon dioxide $\left(\mathrm{CO}_{2}\right)$ emissions of emulsions between palm oil and water were more favorable than that of diesel fuel and it reduced wear of the moving parts [11]. Furthermore, a diesel engine using diesel fuel was tested with the emulsions of rapeseed oil and $10 \%$ of water by volume [12], the results were reported about the increase in engine thermal efficiency, otherwise a considerable reduction in emissions of smoke and $\mathrm{NO}_{\mathrm{x}}$. Other results were reported while using the emulsion of vegetable oil-water obtained by ultrasonic [13]. Besides, the emulsions of honge oil with ethanol and butanol such as ESVO-80 and ESVO-70 were used for an engine [14]. The obtained results showed that, viscosity was lower, volatility was improved, combustion was better and carbon deposits are less.

\section{Blends with Fossil Fuel}

The dilution of vegetable oils with fossil fuel was to reduce viscosity and increase cetane number. An experimental test for a diesel engine fueled with VO in comparison with its blends with fossil diesel fuel while volume of VO changed in the range of 25, 50 and 75 $\%$ was carried out by Ganjehkaviri et al [15]. The results showed that, when engine used diesel fuel-vegetable oil blends, fuel consumption was equal to fossil diesel fuel, but NOx emission was lower than that of fossil diesel fuel. Furthermore, a diesel engine performance and emission characteristics fueled with 20,40 and $60 \%$ of palm oil blending with diesel fuel were evaluated and determined [16]. The result tests also showed, a same thermal efficiency and low emission were observed in case of using blends of a small percentage of palm oil in comparison with diesel fuel.

\section{Hydrotreated Vegetable Oil (HVO)}

HVO has been well-known as a fully potential alternative fuel because of high cetane number, no sulfur and aromatic content. HVO was produced by using Fischer-Tropsch (FT) synthesis [17]. HVO derived from bio-oil sources was considered as long straightchain paraffin (n-paraffin) and non-straight-chain (iso-paraffin) like petro-diesel fuels [18], where converted double bonds to hydrocarbons by saturating was occurred whereas oxygen content was moved by the decarboxylation or decarbonylation reaction to produce $\mathrm{C}_{17} \mathrm{H}_{36}$, and dehydration to produce $\mathrm{C}_{18} \mathrm{H}_{38}$. Generally, the storage stability of renewable paraffinic fuels was better and more acceptable easily by fuel distributors, engine designers, and manufacturers than biodiesels. However, the absence of sulfur was a primary cause of low lubricity [19] but the similar methods applied to improve the lubricity of ultra-low sulfur fossil fuel could be used for HVO [20]. 


\section{Preheated Vegetable Oil}

Dramatically reducing the cost of vegetable oils due to bypassing the converting of biooils into biodiesel has increased the potential of VOs. However, the disadvantage of VO was high viscosity because with current engine design for low viscosity fuel, VOs cause deposit residues on the injectors. To avoid above conditions, the heating method for vegetable oils was proposed [21]. For heating method, palm oil and rapeseed oil as alternative fuel for a diesel engine was used [22], and they were concluded that, the test engine performance was acceptable but in short term of operation. However, these oils caused deposits on piston head and cylinder, sticking of piston rings if operations with long time. Heated neat jatropha and kharanja oils were used for a test diesel engine, Astrup et al [23] denoted that a viscosity reduction was about 80-90\% while preheated up to $90{ }^{\circ} \mathrm{C}$, and at this temperature, their properties were equal to diesel fuel. Preheated raw rapeseed oil (RRO) to $100{ }^{\circ} \mathrm{C}$ was considered as fuel [24], and was shown that the preheating method of vegetable oils affected positively the engine power and emissions. The filter-clogging problem was settled by preheating vegetable oils before injection [25].

Based on the analysis of methods of using pure vegetable oil for diesel engine, the heating method can be considered as the simplest. Thus, this study used heating method for improving the disadvantages of vegetable oil. If vegetable oils, especially inedible oils, are used for diesel engines, it will reduce the environmental pollution and increase the self-provided capacity of fuel for domestic waterway transportation means, generator, or agriculture machine in Mekong Delta, South, and Vietnam.

\section{MATERIALS AND METHOD}

\section{Materials}

Among the plants given vegetable oils and seed oils can be grown in Vietnam, coconut, jatropha, soybean, rubber and peanut trees are considered as favorite ones. However, the coconut trees are planted primarily in the Southern areas in Vietnam and several countries in Southeast Asia. Coconut trees are widely planted in the tropics, along the coast and in the islands of 90 countries, with more than 11 million hectares, mostly concentrated in the Asia Pacific. Ten countries with the largest area of growing coconut in the world are Indonesia, Philippines, India, Sri Lanka, Brazil, Thailand, Papua New Guinea, Malaysia, Vietnam, and Vanuatu. Three of them for leading are Indonesia, Philippines, India where have more than 1 million hectares of growing coconut trees and get over $80 \%$ of quantity in the world. However, coconut productivity of the countries such as India, Sri Lanka, and Vietnam has much higher than that of others. Productivity of coconut fruits per hectare in a year of Vietnam is given in Table 1 and rate of productivity in comparison with other countries in the world is shown in Figure 2.

Table 1 and Figure 2 show that, although Vietnam is the sixth country about the area of growing coconut trees, but Vietnam is the fourth of the rate of productivity. Therefore, Vietnam is a country with large potential of the coconut oil sources. Hence, if coconut oil is used as fuel, it will not only create the source of alternative fuel, reduce the dependence on fossil fuel but also reduce the toxic emissions. Based on the potential of coconut oil sources, this work uses heated raw coconut oil for a diesel engine for evaluating engine performance and emissions. The coconut oil properties at $30{ }^{\circ} \mathrm{C}$ in comparison with fossil diesel fuel are given in Table 2. 
Table 1. Area and productivity of coconut in some countries.

\begin{tabular}{lrc}
\hline Countries & Area (hectare) & $\begin{array}{c}\text { Productivity } \\
\text { (fruits/ hectare/year) }\end{array}$ \\
\hline Indonesia & $3,800.000$ & 4.000 \\
Philippines & $3,560.000$ & 3.719 \\
India & $1,900.000$ & 7.748 \\
Srilanka & 395.000 & 7.346 \\
Thailand & 247.000 & 4.800 \\
Vietnam & 144.800 & 8.294 \\
\hline
\end{tabular}

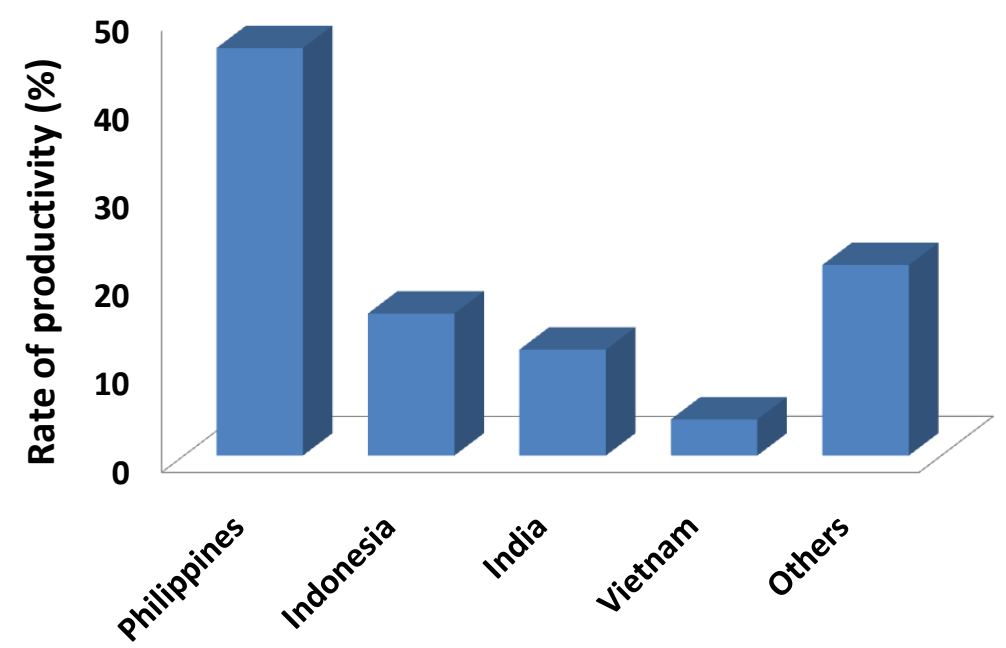

Figure 2. Rate productivity of coconut in the world.

Table 2. Coconut oil and diesel fuel properties at $30{ }^{\circ} \mathrm{C}$.

\begin{tabular}{llcc}
\hline \multicolumn{1}{c}{ Fuel } & $\begin{array}{l}\text { ASTM } \\
\text { standards }\end{array}$ & Coconut oil & Diesel fuel \\
\hline Lower heating value $(\mathrm{MJ} / \mathrm{kg})$ & D240 & 37.8 & 42 \\
Kinematic viscosity $(\mathrm{cSt})$ & D445 & 31 & 4.0 \\
Surface tension $(\mathrm{mN} / \mathrm{m})$ & D971 & 34 & 26 \\
Density $\left(\mathrm{g} / \mathrm{cm}^{3}\right)$ & D1298 & 0.91 & 0.85 \\
Cetane number & D613 & 40 & 46 \\
Flash point $\left({ }^{\circ} \mathrm{C}\right)$ & D93 & 200 & 68 \\
Cloud point $\left({ }^{\circ} \mathrm{C}\right)$ & D 97 & 21 & -7 \\
Distillation temperature $90 \%$ vl $\left({ }^{\circ} \mathrm{C}\right)$ & D 86 & 360 & 362 \\
Copper plate corrosion & D 130 & 1 & 1 \\
Carbon $($ wt.\%) & D5291 & 75.4 & $83.5-87.0$ \\
Hydrogen $(w t . \%)$ & D5291 & 11.8 & $11.5-14.0$ \\
Oxygen (wt.\%) & D5291 & 11.6 & 0 \\
Sulfur $($ wt.\%) & D4294 & 0.01 & $0.02-0.05$ \\
\hline
\end{tabular}

It can be observed from Table 2 that; some advantages of coconut oil are containing oxygen content in molecular and non-sulfur. However, its density, surface tension and kinematic viscosity at low temperature are much higher and cetane number is lower than those of diesel fuel. Actually, the atomization, and mixture are primarily 
affected by fuel surface tension and fuel kinematic viscosity. Poor atomization and mixture will result in the incomplete combustion, increasing the toxic emission and exhaust gas temperature. Thus, three parameters such as density, kinematic viscosity, surface tension are most important. However, the disadvantages of coconut oil can be improved by the heating method.

\section{Method}

To evaluate and determine the most suitable temperature for heating coconut oil based on viscosity, density and surface tension as a function of temperature, some procedures are used. The ASTM D1298 standard with an accuracy of three decimal for measuring density, the ASTM D 445 standard with an accuracy of 0.02 cst and 0.0359 of viscometer constants for measuring kinematic viscosity, Du Nouy ring method with a tension meter based on the ASTM D971 standard for measuring surface tension are used. The above indicators of coconut oil are determined in range of 40 to $120{ }^{\circ} \mathrm{C}$ and repeated three times to take the average value. The relationship between coconut oil physical properties and temperature are plotted in Figure 3, 4 and 5.

It can be observed from Figure 3, Figure 4, and Figure 5 that, kinematic viscosity of coconut oil at $100{ }^{\circ} \mathrm{C}$ is similar to, although surface tension is $2 \mathrm{mN} / \mathrm{m}$ higher and density is $0.013 \mathrm{~g} / \mathrm{cm}^{3}$ higher than those of diesel fuel at room temperature. These values of coconut oil at $80{ }^{\circ} \mathrm{C}$ are much higher in comparison with diesel fuel. However, at 120 ${ }^{\circ} \mathrm{C}$, the reduction in viscosity, density, surface tension needs to be considered. Therefore, heated coconut oil at $80{ }^{\circ} \mathrm{C}$ (HCO_t80), $100^{\circ} \mathrm{C}$ (HCO_t100) and $120^{\circ} \mathrm{C}$ (HCO_t120) are used for this experiment in order to determine the effect of fuel heating temperature on test engine performance and emission characteristics.

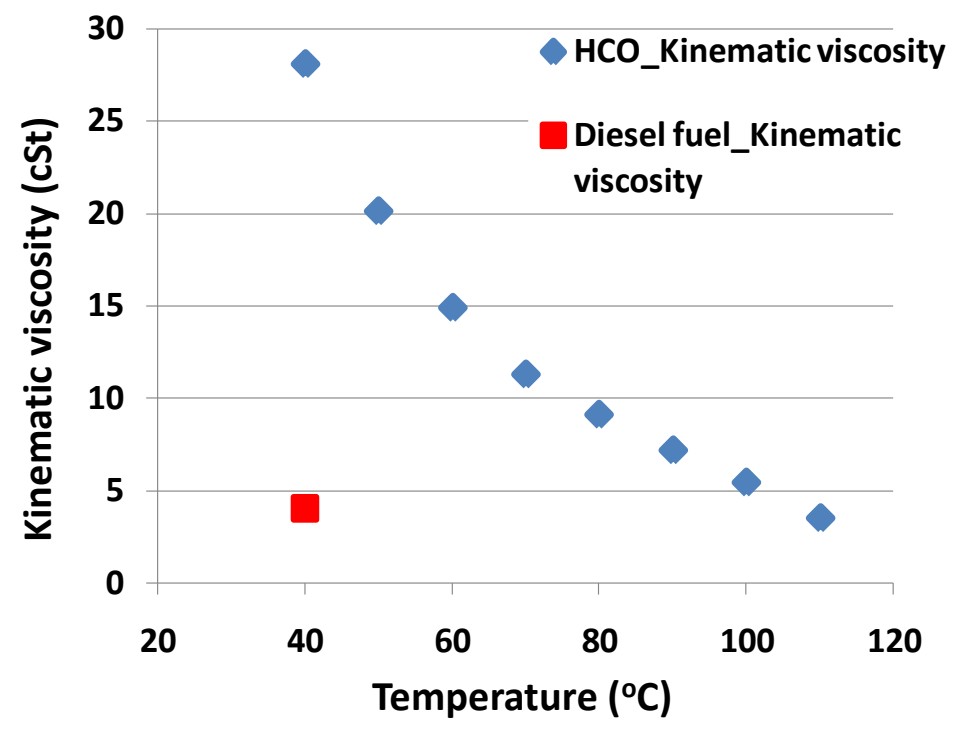

Figure 3. Raw coconut oil kinematic viscosity as a function of temperature. 


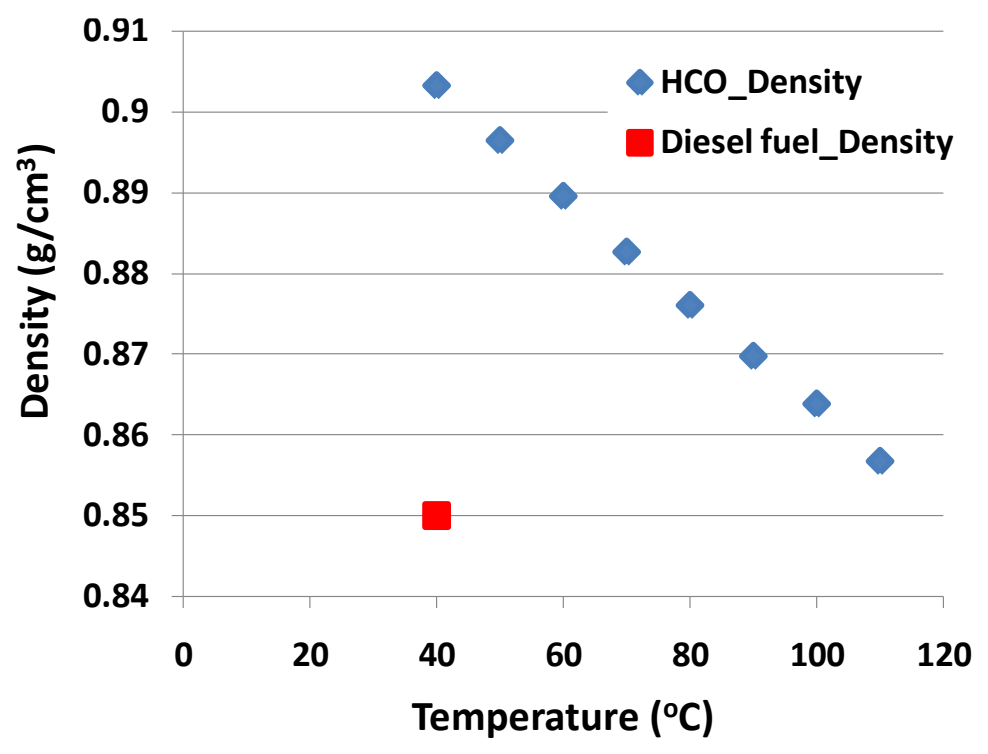

Figure 4. Raw coconut oil density as a function of temperature.

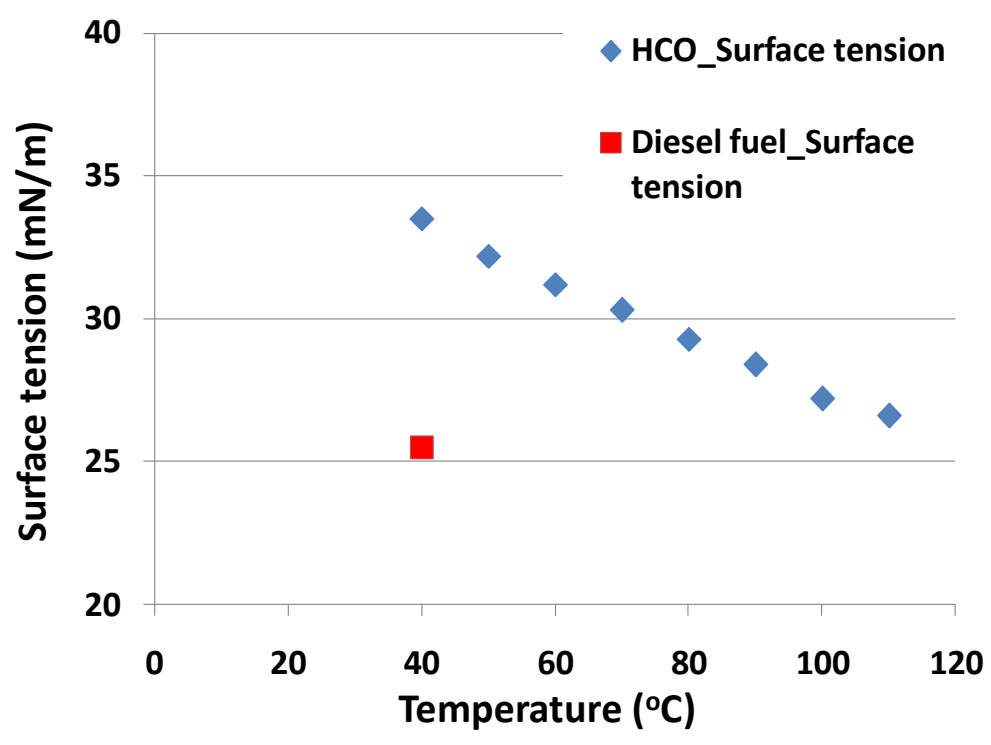

Figure 5. Raw coconut oil surface tension as a function of temperature.

\section{EXPERIMENTAL SETUP}

In this study, the experiment with a test diesel engine to evaluate the engine performance and emission characteristic is carried out on test-bed at Internal Combustion Engine Key Lab. The D243 diesel engine with $80 \mathrm{hp}$ of power, which may be installed on the small ships or vessels with tonnage of about 100 tons available in the South, Vietnam, is considered as a test engine and described in Table 3.

This test engine is fueled with heated raw coconut oil HCO_t80, HCO_t100, and HCO_t120, respectively and diesel fuel (DO) at different load at $1500 \mathrm{rpm}$ of speed. During experiments, the test engine is provided fully with lubricant and cooling aiming at maintaining the test diesel engine stability. The technical, economic and emission features of the D243 engine are determined versus the measurement device and electronic sensor. Each measurement was repeated three times to aim at obtaining the highly exact 
average results. The diagram of setting up the experiment on AVL engine test-bed is shown in Figure 6.

Table 3. Specifications of D243 diesel engine.

\begin{tabular}{ll}
\hline Type & $\begin{array}{l}\text { Vertical, 4-stroke, } 4 \text { cylinders, direct injection, } \\
\text { cooled by water, compression ignition }\end{array}$ \\
\hline Model & D243 from Belarus \\
Rated Power & $80 \mathrm{hp}$ \\
Maximum speed & $2200 \mathrm{rpm}$ \\
Bore/ Stroke & $110 / 125 \mathrm{~mm}$ \\
Compression ratio & $16.7: 1$ \\
\hline
\end{tabular}

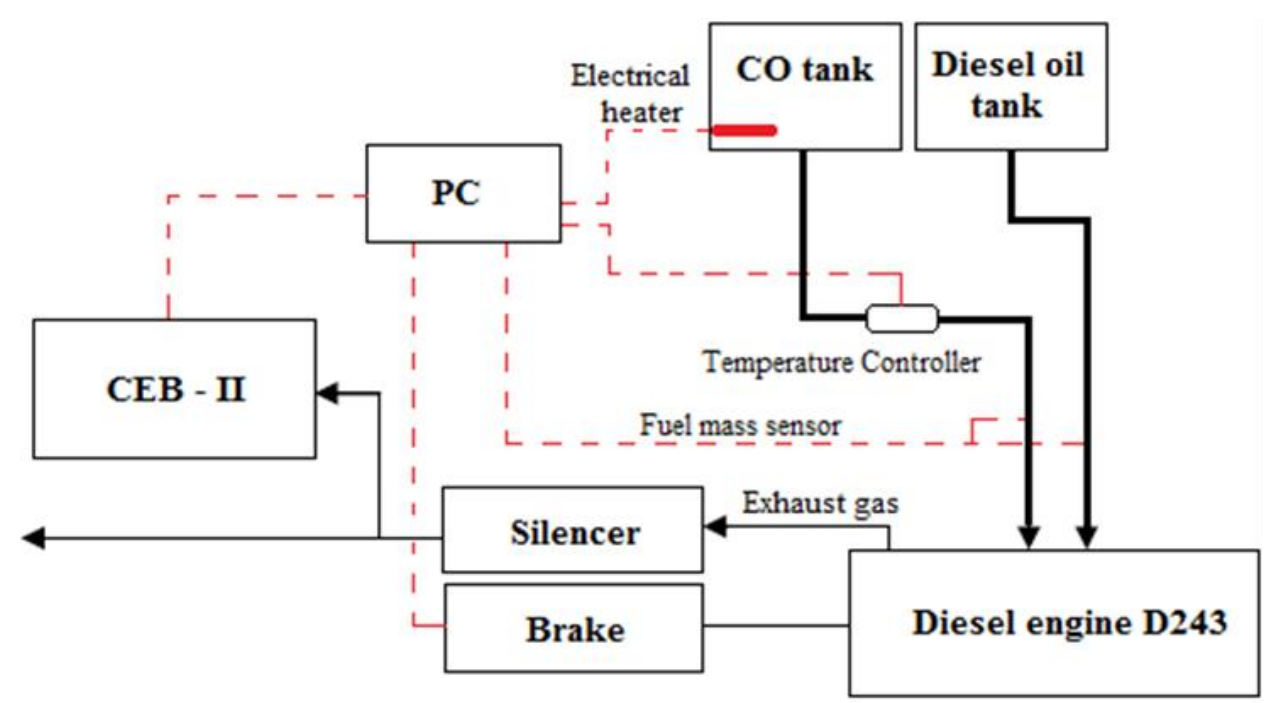

(a)

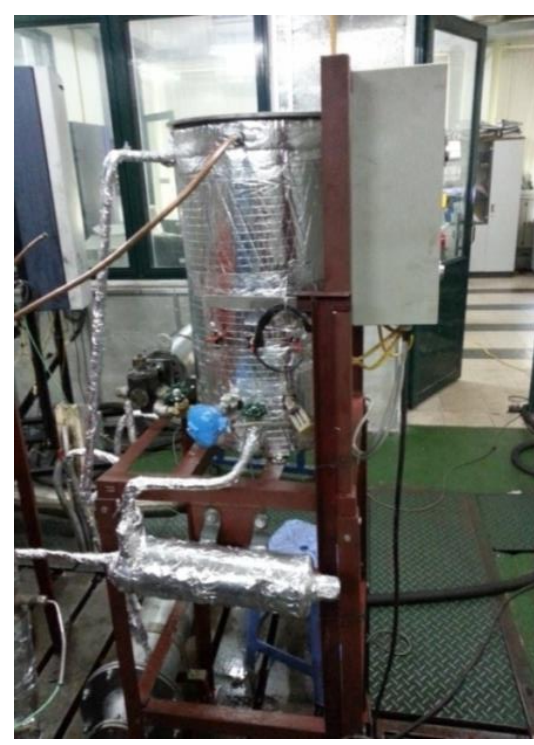

(b)

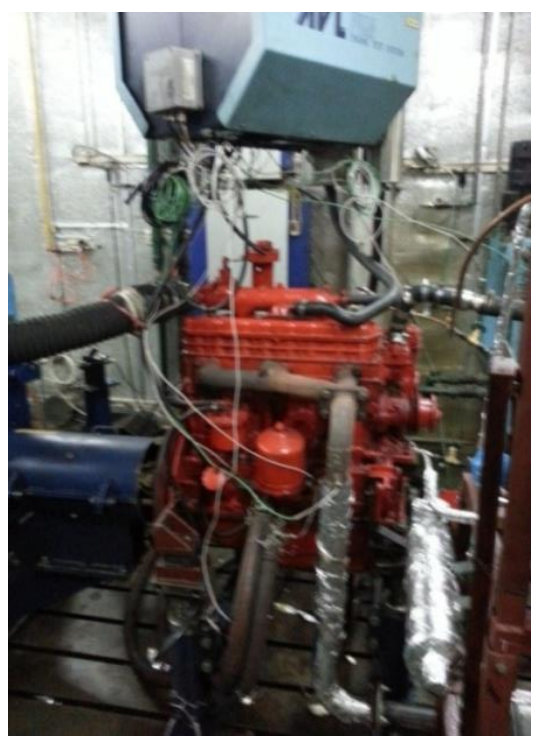

(c)

Figure 6. (a) Schematic of experimental setup; (b) integration of exhaust-electricity energy-based-heating system of coconut oil and; (c) experimental setup on D243 testbed with sensors. 
The function of cluster brake is to work as generator and engine mode, therefore it can be used to make the experiments on the engine test-bed. Cabinets CEB-II is a system containing the modules such as blocks of heating (HSU), diagnostic and control for analyzing accurately the exhaust components include carbon monoxide (CO), nitrogen oxides (NO and $\mathrm{NO}_{\mathrm{x}}$ ), hydrocarbons (HC) accuracy and smoke. This CEB-II analyzer is also installed with computer fitted GEM110 software, and it is done via digital signal. The parameters of analyzer accuracy are given in Table 4 .

Table 4. Emission measuring range and accuracy of analyzer.

\begin{tabular}{llrc}
\hline Equipment & Parameters & Measuring range & Accuracy \\
\hline \multirow{2}{*}{ Exhaust gas } & Carbon monoxide $(\mathrm{CO})$ & $0-10.000 \mathrm{ppm}$ & $2 \mathrm{ppm}$ \\
analyzer & Hydrocarbon (HC) & $0-20.000 \mathrm{ppm}$ & $5 \mathrm{ppm}$ \\
Smoke meter & Nitrogen oxide (NOx) & $0-5000 \mathrm{ppm}$ & $1 \mathrm{ppm}$ \\
& Smoke & $0-99.8 \%$ & $0.2 \%$ \\
\hline
\end{tabular}

\section{RESULTS AND DISCUSSION}

\section{Engine Performance}

The engine performance with $\mathrm{HCO}$ was determined and evaluated about engine power, specific fuel consumption (SFC), thermal efficiency (TE) at different load of the engine. In the case of using $\mathrm{HCO}$ as fuel, smaller lower heating value and cetane number is primary cause to lead to reduction in engine power even $\mathrm{HCO}$ is injected at $80-120{ }^{\circ} \mathrm{C}$ aiming at decreasing viscosity, increasing the vaporization rate, mixture, and combustion. In Figure 7, engine power as using $\mathrm{HCO}_{-} \mathrm{t} 80$ is higher than that of HCO_t100 and HCO_t120, it is explained due to HCO_t80 density is larger, hence the fuel mass is larger as well as the energy content at constant volume of injected fuel into the cylinder is larger. However, in comparison with DO, engine power as using HCO decreases 8.49-13.45\%. $\mathrm{HCO}$ with larger viscosity, density and surface tension may result in a poor atomization and vaporization, and nebulization, as well as the temperature in combustion chamber is low at low load.

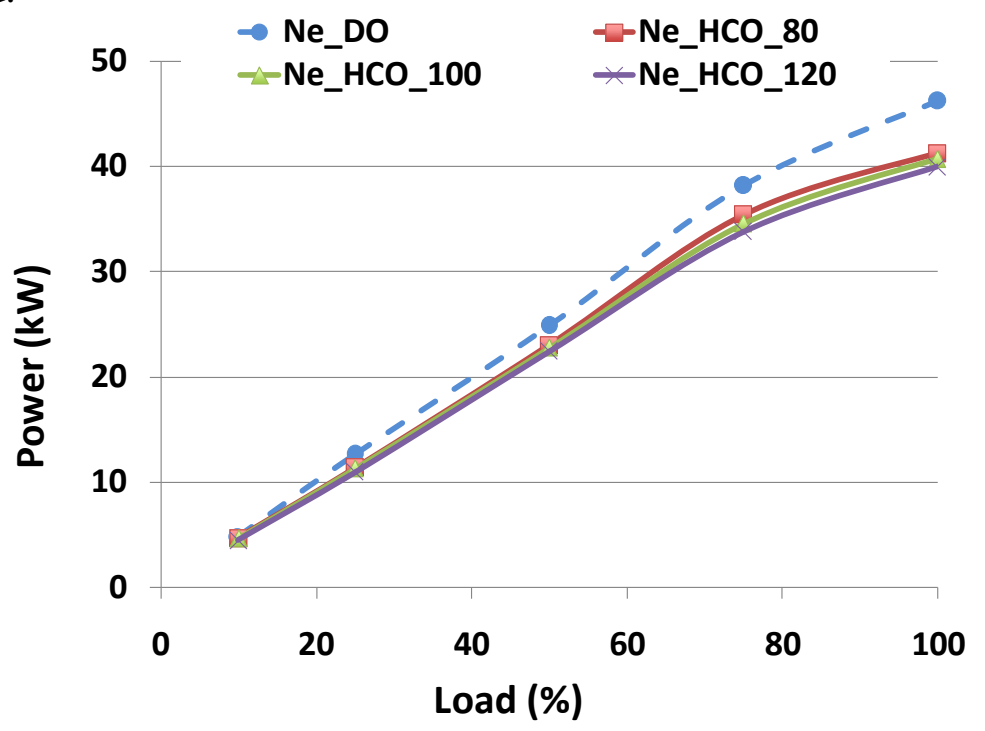

Figure 7. Relationship between $\left(\mathrm{N}_{\mathrm{e}}\right)$ and engine load. 
In fact, the injection time and quality play an important part in engine operation, especially at conditions of operation such low load and regimes because the injected fuel amount is small. Moreover, injection time is separated to three main period phases: a first period phase is considered as the opening of injectors, at second period phase is the main one, and the last is the closing period phase. As the total time of injection process is small, the first period phase and last period phase is also small. Thus, the poor atomization, vaporization, and nebulization along with lower cetane number are the consequence causing bad combustion and engine power loss.

The SFCs of a test diesel engine operated at different load and fueled with different HCO compared to DO are plotted in Figure 8. It can be seen from Figure 8 that, SFCs are proportional inversely to the engine load, however, at higher loads, SFCs increases. These results may be explained because of an increase in fuel mass in comparison with same-obtained-power in test time, besides the heat losses of engine run at higher loads is less than that of lower loads. The SFC for HCO_t80, HCO_t100, and HCO_t120 is higher than that of DO by 6.59, 5.40 and $6.14 \%$, respectively. It is observed due to higher density of HCO resulted in higher weight of HCO.

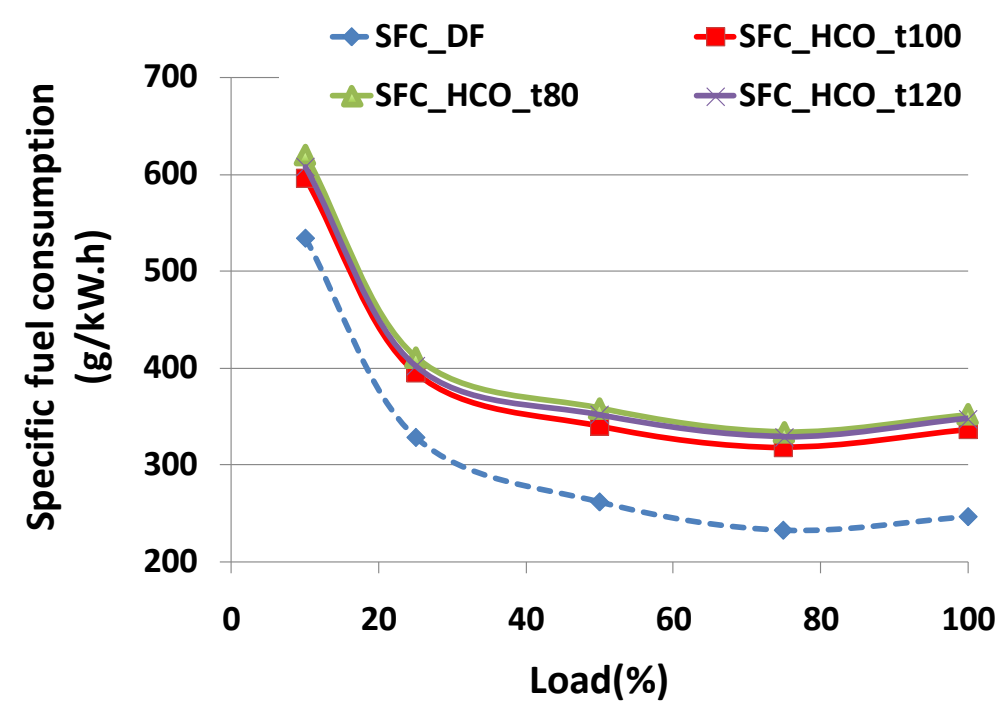

Figure 8. Relationship between SFC and engine load.

Moreover, the higher densities of HCO_t80, HCO_t100 result in higher mass of injection although at the same fuel volume and injection pressure, otherwise $\mathrm{HCO}$ cetane number, and heat content are lower than those of DO. Although the density of HCO_t120 is slightly lower than that of DO but the obtained power from HCO_t120 is also lower in comparison with in case of using HCO_t80 and HCO_t100. Therefore, the fuel consumption volume is $2.98 \%$ higher for $\mathrm{HCO}$ t 80 , is $2.27 \%$ for HCO_t100. Maximum SFC of HCO_t80 is 620.13 (g/kW.h), of HCO_t100 is 596.08 (g/kW.h), HCO_t120 is 608.21 (g/kW.h) in comparison with 533.75 (g/kW.h) of DO. Similar results were also presented by some researchers $[6,26]$.

The thermal efficiency (TE) of a diesel engine is calculated as in Eq. (1).

$T E=\frac{N_{e}}{Q}=\frac{3600}{(S F C)(L H V)}$ 
where Q $(\mathrm{kW})$ is achieved energy with supplied fuel mass; LHV (MJ/kg) is lower heating value. The thermal efficiency (TE) of test engine considered as a function of engine load while fueled with different fuels is plotted in Figure 9. The maximum thermal efficiency is $29.57 \%$ for HCO_t $80,31.06 \%$ for HCO_t100, and $30.02 \%$ for HCO_t20 as compared to $38.73 \%$ for DO when engine run at around $80 \%$ of load. This may be understood due to the cetane number and heating value of HCO are lower than those of DO. At lower loads, thermal efficiency (TE) of all test fuels increase, but these values decrease as engine run at high loads.

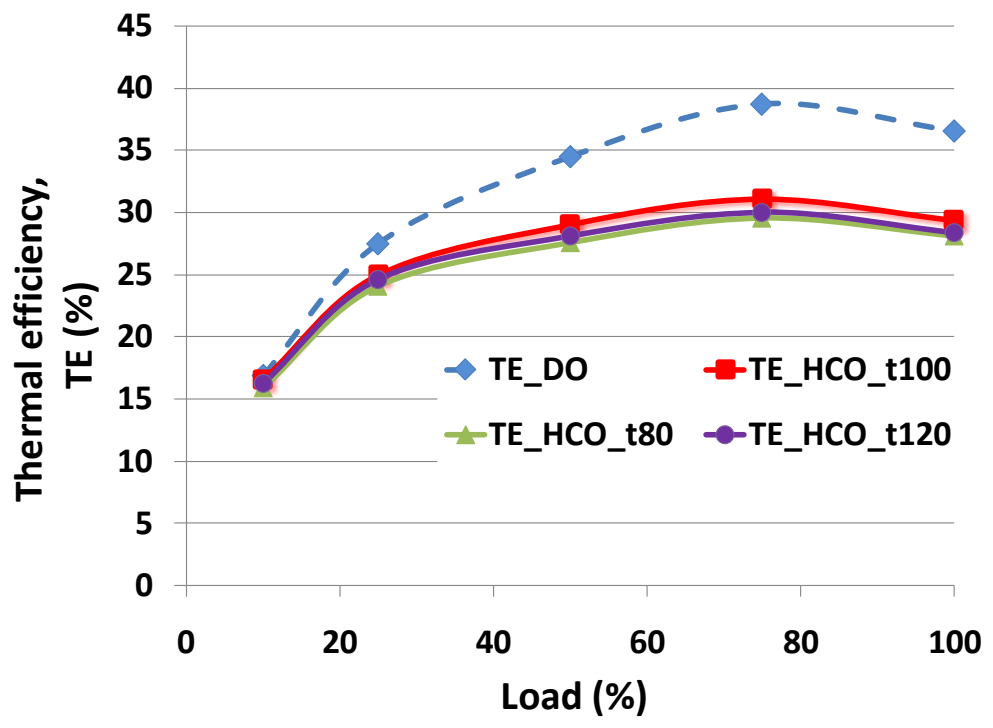

Figure 9. Relationship between TE and engine load.

\section{Emission Characteristics}

The carbon monoxide emission (CO) and hydrocarbon emission (HC) features of test engine fueled with HCO and DO are shown in Figure 10 and Figure 11.

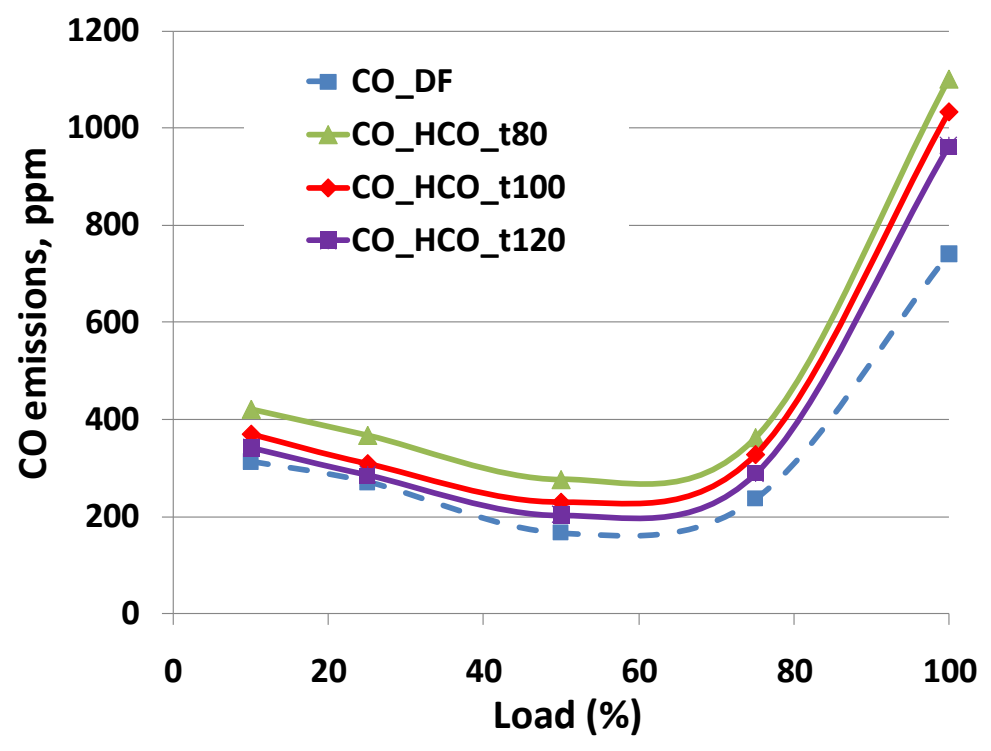

Figure 10. Relationship between carbon monoxide emission and engine load. 


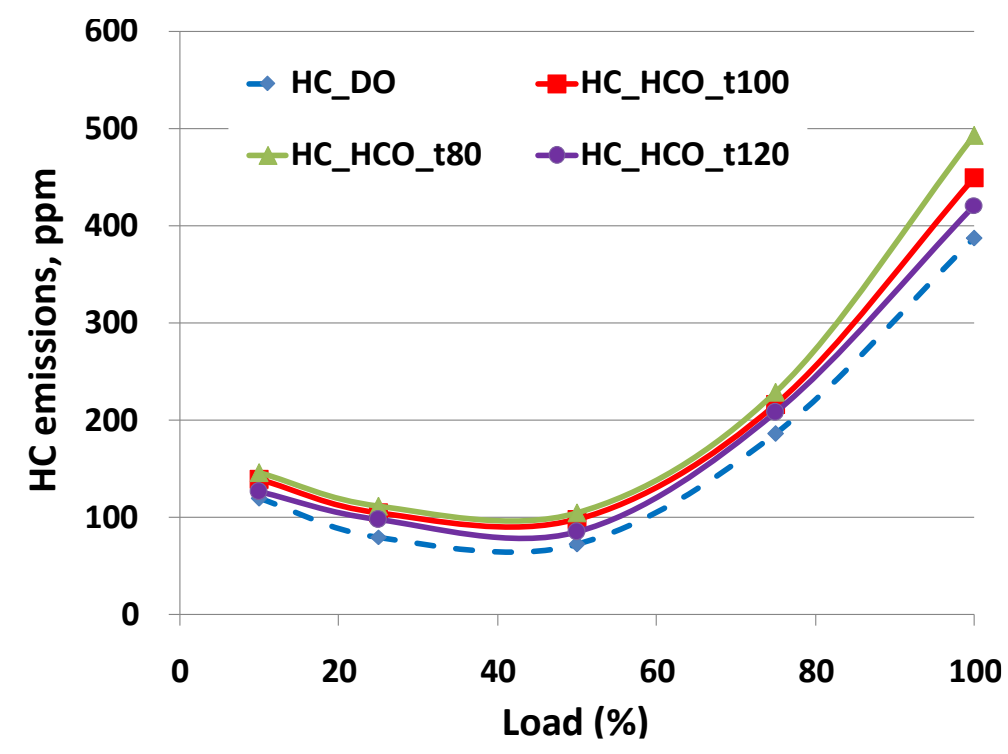

Figure 11. Relationship between hydrocarbon emission and engine load.

Test engines were conducted and determined the emission characteristics using HCO and DO, higher TE and lower SFC for DO in comparison with lower TE and higher SFC for HCO were observed in Figure 8 and Figure 9. TE of HCO_t80 is lowest but SFC of HCO_t80 is highest. Lower calorific value of coconut oil may be the main cause resulting in necessary increase of the fuel volume aiming at maintaining the same input energy compared with the case of using DO to the engine. This reason is explained due to high kinematic viscosity, density and surface tension of $\mathrm{HCO}$ t 80 , which result in poor atomization, low evaporation because of larger fuel surface energy and droplets and it is inadequate mixture of coconut oil and compressed air. For HCO_t120, due to lower kinematic viscosity (about $1.2 \mathrm{cSt}$ ), therefore ultra-dilution fuel may strongly affect the injection, and this is the cause leading to the reduction in TE but increase in SFC compared to HCO_t100. However, TE of HCO_t100 is higher, otherwise, SFC is lower than those of HCO_t80 and HCO_t120 but is not so equal as DO's. The primary reason may be the improved fuel atomization, evaporation, mixture up to the most suitable value of viscosity and surface tension.

The CO emissions with $\mathrm{HCO}$ and DO at changing loads of engine are presented in Figure 10. The $\mathrm{CO}$ emissions are not much different for these fuels at lower loads, but at higher loads, $\mathrm{CO}$ emission for $\mathrm{HCO}$ is higher than that of DO. The $\mathrm{CO}$ produced for HCO_t80 is $420-1101$ ppm higher, for HCO_t100 is $370-1034 \mathrm{ppm}$ higher, for HCO_t120 is $341-962$ ppm higher in comparison with $312-740 \mathrm{ppm}$ of DO. With average results, produced $\mathrm{CO}$ as using $\mathrm{HCO}$ t 80 is $47.71 \%$ higher, $\mathrm{HCO} \_\mathrm{t} 100$ is 29.80 $\%$ higher, HCO_t120 is $17.76 \%$ higher than that of DO. It can be observed from Figure 10, similar to $\mathrm{CO}$ emissions, produced HC as using HCO_t80 is $104-493$ ppm higher, HCO_t100 is $98-449$ ppm higher, HCO_t120 is $84-421$ ppm higher in comparison with $72-387 \mathrm{ppm}$ of DO. This occurs due to at lower load, the temperature of combustion chamber is low. Therefore, fuel combustion is more difficult. At higher temperature, engine performance is improved, however while further loading, the supplied fuel is excess the required fuel mass resulting in forming more smoke. This leads to be lack of oxygen that prevent from converting $\mathrm{CO}$ into $\mathrm{CO}_{2}$ and burning fuel, hence $\mathrm{CO}, \mathrm{HC}$ emissions dramatically increase. Produced smoke and $\mathrm{NO}_{\mathrm{x}}$ emission characteristics of 
test engine using DO and $\mathrm{HCO}$ as function of load are presented in Figure 12 and Figure 13 , respectively.

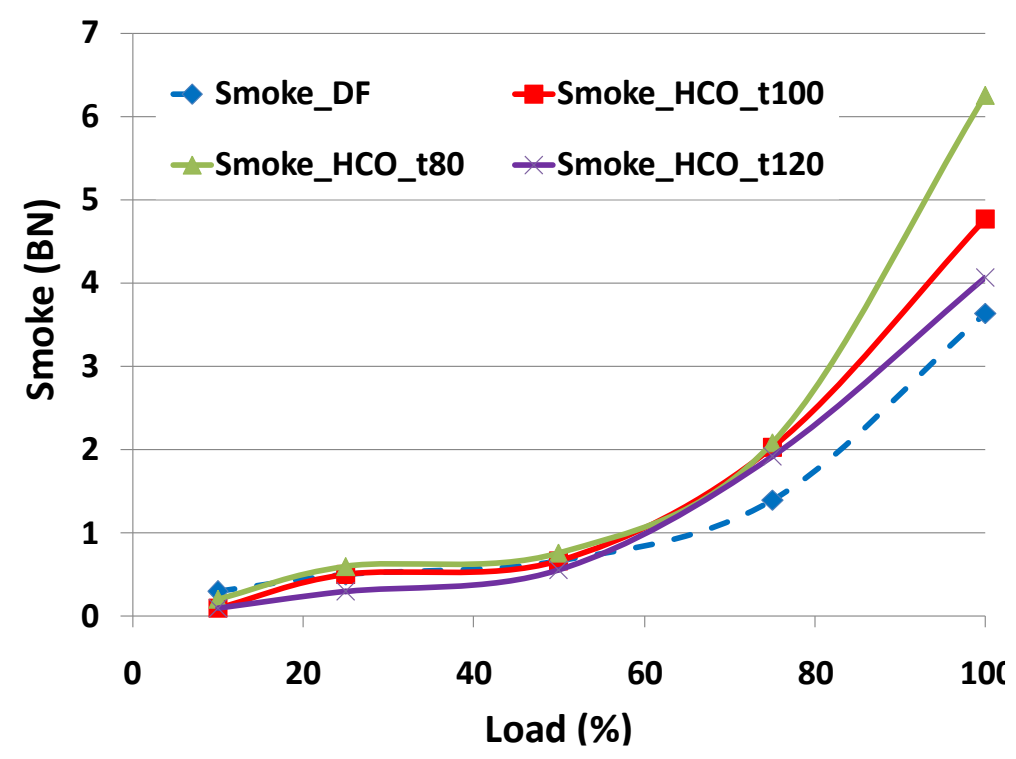

Figure 12. Relationship between smoke emission and engine load.

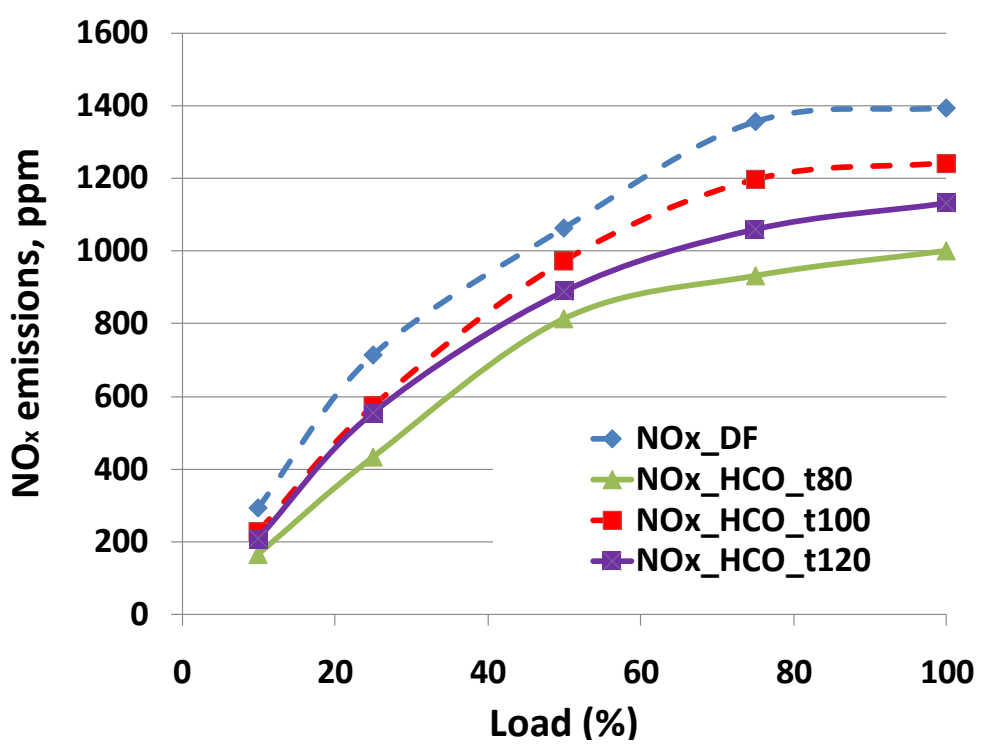

Figure 13. Relationship between $\mathrm{NO}_{\mathrm{x}}$ emissions and engine load

Smoke is also the result of incomplete and imperfect combustion. Specially, fuel is injected more into the combustion chamber and bulky molecules at higher loads, higher surface tension, and viscosity of HCO leads to lower evaporation, poor atomization. Figure 12 shows that, at lower load, the smoke emission of HCO is lower than that of DO. This may be due to the oxygen presence in molecular of coconut oil compared to DO. As coconut oil is injected with small mass, it is burnt more completely. However, at higher loads, larger coconut oil mass is injected into combustion chamber and incomplete combustion leads to an increase in smoke emission. For HCO, the lowest smoke opacity is observed with HCO_t120. The average smoke emission increases by $24.12 \%$ for HCO_t80, $10.38 \%$ for HCO_t100, $4.82 \%$ for HCO_t120, respectively. This result proves 
that, added oxygen into vegetable oil in combination with lean mixture in case of using HCO_t120 gives the lowest smoke emission. However, contrary result occurs with HCO_t80 because of rich mixture.

Figure 13 shows that, $\mathrm{NO}_{\mathrm{x}}$ emissions of $\mathrm{HCO}_{-} \mathrm{t} 100$ increases in comparison with HCO_t80 and HCO_t120. This increase in $\mathrm{NO}_{\mathrm{x}}$ emissions for HCO_t100 may be due to HCO_t100 physical properties are the closest to DO's although oxygen content and cetane number are unchanged. However, the injection rate, spray characteristic, heating value and cetane number are the interaction factors that have an effect on combustion of fuel. Therefore, the consonance of above factors results in increasing the $\mathrm{NO}_{\mathrm{x}}$ emissions for HCO_t100 in comparison with HCO_t80 and HCO_t120. The more engine load increases, the more the $\mathrm{NO}_{\mathrm{x}}$ emissions increase. With average results, the $\mathrm{NO}_{\mathrm{x}}$ emissions of HCO_t100 is $14.63 \%$ lower than that of DO but 21.97 and $8.14 \%$ higher than that of HCO_t80 and HCO_t120, respectively.

\section{CONCLUSION}

Based on this study, it is seen clearly that the most suitable heating temperature for coconut oil is $100{ }^{\circ} \mathrm{C}$. While using HCO_t100 as fuel in test engine at changing loads such as $10,25,50,75$ and $100 \%$ of load and $1500 \mathrm{rpm}$ of speed; engine power and thermal efficiency reduction was $9.52 \%$ and $4.28 \%$ respectively, in comparison with DO. The specific fuel consumption is $5.40 \%$ higher, emission of CO is $29.80 \%$ higher, $\mathrm{HC}$ is $19.26 \%$ higher, smoke is $10.38 \%$ higher; otherwise, $\mathrm{NO}_{\mathrm{x}}$ emission is $14.63 \%$ lower than those of diesel fuel. Although cetane number and heating value of coconut oil are lower than those of diesel fuel but raw coconut oil can be considered as fuel for replacement of fossil fuel in diesel engines if heated aiming at environmental pollution reduction because of vegetable oil's biodegradable, renewable, available characteristic compared to fossil fuel. This heating method is solved by using electrical energy or utilizing the exhaust gas energy.

\section{ACKNOWLEDGEMENT}

The authors acknowledge Ho Chi Minh city University of Transport, School of Transportation Engineering - Hanoi University of Science and Technology, National Key Laboratory for Refining and Petrochemical Technologies for supporting this research.

\section{REFERENCES}

[1] Agarwal AK, Agarwal RA, Gupta T, Gurjar BR. Biofuels: Technology, Challenges and Prospects. Springer. 2017.

[2] Panwar NL, Kaushik SC, Kothari S. Role of renewable energy sources in environmental protection: a review. Renewable and Sustainable Energy Reviews. 2011; 15: 1513-1524.

[3] Hoang AT. The Performance of Diesel Engine Fueled Diesel Oil in Comparison with Heated Pure Vegetable Oils Available in Vietnam. Journal of Sustainable Development. 2017; 10: 93-98.

[4] Ramadhas AS, Jayaraj S, Muraleedharan C. Use of vegetable oils as IC engine fuels - a review. Renewable energy. 2004; 29: 727-742.

[5] Balaji G. ,Cheralathan M. Potential of various sources for biodiesel production. Energy Sources, Part A Recover. Util. Environ. Eff. 2013; 35: 831-839. 
[6] Hoang AT ,Le VV. The Performance of A Diesel Engine Fueled With Diesel Oil, Biodiesel and Preheated Coconut Oil. International Journal of Renewable Energy Development. 2017; 6: 1.

[7] Manjunath H, Hebbal O, Reddy KH. Process Optimization for Biodiesel Production from Simarouba, Mahua, and Waste Cooking Oils. International journal of green energy. 2015; 12: 424-430.

[8] Dubey P ,Gupta R. Study of the performance and emission characteristics for a dual fuel powered single cylinder diesel engine. International Journal of Automotive and Mechanical Engineering. 2016; 13: 3373.

[9] Khalid A, Tajuddin ASA, Jaat N, Manshoor B, Zaman I, Hadi SAA, Nursal RS. Performance and emissions of diesel engine fuelled with preheated biodiesel fuel derived from crude palm, jatropha, and waste cooking oils. International Journal of Automotive and Mechanical Engineering. 2017; 14: 4273-4284.

[10] Pattanaik BP, Jena J, Misra RD. The effect of oxygen content in soapnut biodieseldiesel blends on performance of a diesel engine. International Journal of Automotive and Mechanical Engineering. 2017; 14: 4574-4588.

[11] Mosaro MH, Kalam MA, Masjuki HH, Ashraful AM, Rashed MM, Imdadul HK, Monirul IM. Implementation of palm biodiesel based on economic aspects, performance, emission, and wear characteristics. Energy Conversion and Management. 2015; 105: 617-629.

[12] Anbarasu A ,Karthikeyan A. Diesel engine performance and emission evaluation using Canola biodiesel emulsion fuel. Australian Journal of Mechanical Engineering. 2016; 14: 174-181.

[13] Dewangan A ,Mallick A. Ultrasonic-assisted production of biodiesel from Manilkara Zapota (L.) seed oil. Energy Sources, Part A: Recovery, Utilization, and Environmental Effects. 2017; 39: 1594-1601.

[14] Rao N, Premkumar BS, Yohan M. Performance and Emission Characteristics of Straight Vegetable Oil-Ethanol Emulsion in a Compression Ignition Engine. ARPN Journal of Engineering and Applied Sciences. 2012; 7: 447-452.

[15] Ganjehkaviri A, Mohammad NMJ, Seyed EH, Anas BM. Performance Evaluation of Palm Oil-Based Biodiesel Combustion in an Oil Burner. Energies. 2016; 9: 97.

[16] Iqbal AM, Zainal ZA, Mazlan M, Abdullah MMAIB, Salim MS, "Performance and emission characteristics of diesel engine running on blended palm oil," in Advanced Materials Research, 2013, vol. 795, pp. 164-169: Trans Tech Publ.

[17] Vo TC, Chinda, Charoenphonphanich, Preechar, Karin, Sato S, Kosaka H. Optical study on combustion characteristics of hydrotreated vegetable oil and blends under simulated CI engine conditions and various EGR. Journal of Mechanical Science and Technology. 2017; 31: 4521-4531.

[18] Walther G, Schatka A, Spengler TS. Design of regional production networks for second generation synthetic bio-fuel-A case study in Northern Germany. European Journal of Operational Research. 2012; 218: 280-292.

[19] Jaroonjitsathian S, Saisirirat P, Sivara K, Tongroon M, Chollacoop N, "Effects of GTL and HVO Blended Fuels on Combustion and Exhaust Emissions of a Common-Rail DI Diesel Technology," SAE Technical Paper0148-7191, 2014.

[20] Vojtisek-Lom M, Beránek V, Mikuška P, Kř̌mal K, Coufalík P, Sikorová J, Topinka J. Blends of butanol and hydrotreated vegetable oils as drop-in replacement for diesel engines: Effects on combustion and emissions. Fuel. 2017; 197: 407-421. 
[21] Hoang AT, Nguyen VT. Emission Characteristics of a Diesel Engine Fuelled with Preheated Vegetable Oil and Biodiesel. Philippine Journal of Science. 2017; 146: 475-482.

[22] Sivalakshmi S ,Balusamy T. Performance and Emission Characteristics of a Diesel Engine Fuelled by Neem Oil Blended with Alcohols. International Journal of Ambient Energy. 2011; 32: 170-178.

[23] Astrup TF, Davide T, Roberto T, Alessio B. Life Cycle Assessment of Thermal Waste-to-Energy Technologies: Review and Recommendations. Waste management. 2015; 37: 104-115.

[24] Hazar H ,Aydin H. Performance and emission evaluation of a CI engine fueled with preheated raw rapeseed oil (RRO)-diesel blends. Applied Energy. 2010; 87: 786-790.

[25] Corsini A, Marchegiani A, Rispoli F, Sciulli F, Venturini P. Vegetable oils as fuels in Diesel engine. Engine performance and emissions. Energy procedia. 2015; 81: 942-949.

[26] Singh BP. Performance and emission characteristics of conventional engine running on jatropha oil. Journal of Mechanical Science and Technology. 2013; 27: $2569-2574$. 